\title{
OJED
}

ISSN: 2166-2681 Print/ ISSN: 2690-0408 Online

Volume 9, Issue 1 (2020), pp. 181-183

(C) Journal of Interdisciplinary Studies in Education

http://ojed.org/jise

\section{An Online Doctorate for Researching Professionals: Program Design, Implementation, and Evaluation}

Kumar, S., \& Dawson, K. (2018). AU Press ISBN: 9781771992084

Reviewed by Tolulope Ajayi, Morgan State University, USA

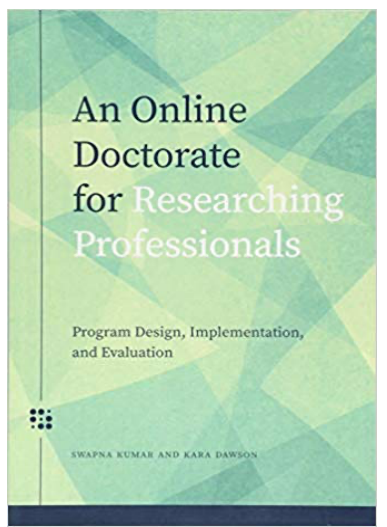

An Online Doctorate for Researching Professional was written with the view of developing new perspectives that would expand the horizon of Ph.D. students in higher education. The authors proposed a framework that can be used to develop online programs that would meet the needs of the working professionals. Online doctoral programs have become necessary because the traditional Ph.D. programs in education were not enough to meet the desires of the working professionals who are interested in furthering their education and carrying out applied research while continuing full-time employment. Kumar and Dawson (2018) saw this as an opportunity after they noticed that the last two decades have witnessed a tremendous development in internet and communication technologies. They believed that these developments could lead to the possibilities for virtual environments that would facilitate doctoral level experiences at a distance. As a result, the authors presented a model that focused on an online professional doctorate program that combined theory, research, and practice. The explanation for the development of an online environment was done using the example of the online professional doctorate in educational technology at the University of Florida (UF EdD EdTech).

The book is divided into three parts; the first part describes the theoretical foundation, design, and model for researching an online 
professional doctorate. The second chapter of this part highlighted the different theories about adult learning and described how the knowledge of these theories cab be used in designing an online professional doctoral curriculum for connecting theory, research, and practice.

Part 2 of the book dwells on the implementation of the online program. Also, it considers the most challenging aspect of online professional doctorate programs, which is the creation of a community of online researching professionals who are scholars. The authors explained the essential design of the community of inquiry (CoI) model that they had adopted for supporting student's sense of belonging to their doctoral program. This part included chapters on fostering scholarly thinking among professionals, and also provided an online curriculum that helps in the promotion of scholarly reading, writing, information literacy, and enculturation. Scholarly thinking was further encouraged in the detailed descriptions of the assignments and activities to show their alignment and support for student scholarly development. The authors described how the integration of designed interactive learning activities, within the course, supported students through candidacy and the dissertation stages. Finally, this section described the structuring of the dissertation that connects theory, research, and practice. The second part contains useful information for online programs. This is however, faulted through the repetition of similar information in different instructional goals.

The third part of the book is the evaluation of an online professional doctorate. This part addresses the maintenance of the quality of an online doctorate, and the assessment of the impact of an online program. The authors (Kumar \& Dawson, 2018) noted that the last two decades have witnessed an increased expansion of online education, which resulted in the development of standards, technical infrastructure, acceptable, and intellectual policies, support for online course development and faculty programs in online teaching.

The book has enhanced the knowledge base and the ability to offer online programs through learning management systems, student information system, synchronous and asynchronous technologies, and mobile applications. Other books that provided a comprehensive overview of various aspects of online education were also acknowledged.

I recommend this book for institutions and individuals that are considering offering an online Ed.D. programs. The book contains supportive examples of the experiences of the authors. The model proposed by the authors, Kumar and Dawson (2018), is not limited to the United States nor education. The guidelines for the program design, implementation, and evaluation described the best practices required for any online graduate program development initiative. 
Tolulope Ajayi is currently a scholar in Higher Education at Morgan State University. She was the coordinator of College Discovery Program, an initiative of Morgan State University that seeks to recruit students into both online and face to face programs.

Email: toaja2@morgan.edu.

Manuscript submitted: December 4, 2019

Manuscript revised: February 14, 2020

Accepted for publication: March 25, 2020 